\title{
Ebstein's anomaly in an asymptomatic nonagenarian: A case report
}

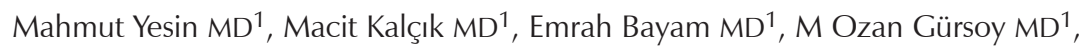 \\ Süleyman Karakoyun MD ${ }^{1}$, Mehmet Özkan MD $^{1,2}$
}

\begin{abstract}
M Yesin, M Kalçık, E Bayam, MO Gürsoy, S Karakoyun, M Özkan. Ebstein's anomaly in an asymptomatic nonagenarian: A case report. Curr Res: Cardiol 2015;2(1):40-42.
\end{abstract}

Ebstein's anomaly (EA) is a rare cardiac congenital malformation characterized by apical displacement of the septal and posterior tricuspid leaflets, resulting in atrialization of the right ventricle. Many congenital cardiac

Cbstein's anomaly (EA) of the tricuspid valve is a rare and complex Congenital heart defect, with an incidence of one in 200,000 live births and accounting for $0.5 \%$ of all congenital cardiac malformations (1). The common feature in all cases of EA is apical displacement of the septal tricuspid leaflet in conjunction with leaflet dysplasia. The displacement of the tricuspid valve results in 'atrialization' of the inflow tract of the right ventricle and consequently produces a variably small functional right ventricle. Many cardiac anomalies may be associated with EA including atrial septal defect, conduction system abnormalities, patent foramen ovale, noncompaction cardiomyopathy, pulmonary stenosis or atresia, and ventricular septal defect (2). Many patients with EA survive and require repair in adulthood (3). Age of presentation varies considerably according to anatomical severity and other associated cardiac anomalies. Clinical presentation includes cyanosis, right-sided heart failure, arrhythmias, decreased exercise tolerance, fatigue, sudden cardiac death and paradoxical embolism (4).

\section{CASE PRESENTATION}

A 92-year-old woman was referred to the authors' outpatient clinic due to the presence of a severe systolic murmur. Her history was unremarkable for cardiac diseases. She was a nonsmoker, nondiabetic and nonhypertensive. She had given birth seven times. On physical examination, there was no cyanosis or clubbing. Apart from a mild pretibial edema, the patient was asymptomatic. Lung sounds were clear and $4 / 6$ systolic murmurs were heard on the right lower sternal border. Her blood pressure was $115 / 60 \mathrm{mmHg}$ and electrocardiography showed sinus rhythm. A chest radiograph revealed cardiomegaly. Laboratory findings, including complete blood count, liver and kidney function tests and urine analysis, were normal. She had not experienced any transient ischemic attack, embolic event or malignant arrhythmia. Transthoracic echocardiography showed a normal left ventricular size and ejection fraction. However, there was a moderate dilation of the right chambers with tethering of the septal and posterior leaflets of the tricuspid valve during systole, causing central coaptation failure and severe regurgitation (Figure 1A, 1B and Video 1, Video 2). An apical four-chamber view showed $14 \mathrm{~mm}\left(12 \mathrm{~mm} / \mathrm{m}^{2}\right)$ apical displacement of the septal leaflet of the tricuspid valve (Figure 1A). A systolic pulmonary artery pressure of $35 \mathrm{mmHg}$ was estimated from the tricuspid regurgitant jet with continuous-wave Doppler imaging (Figure 2A). Tricuspid annular plane systolic excursion was anomalies may be associated with EA. Clinical presentation depends on anatomical severity and other associated cardiac anomalies. Here, a case of EA in an asymptomatic 92-year-old woman who had given birth seven times is presented.

Key Words: Ebstein's anomaly; Echocardiography; Nonagenarian; Tricuspid valve

measured as $23 \mathrm{~mm}$ using $\mathrm{M}$-mode echocardiography (Figure 2B). Other congenital cardiac malformations, such as patent foramen ovale, atrial septal defect, pulmonary venous return anomaly, etc, were excluded by transesophageal echocardiography. Computed tomography pulmonary angiography showed normal pulmonary arteries. There was no additional congenital cardiac anomalies. The diagnosis of isolated type A EA was defined according to Carpentier's classification. Because of the absence of cyanosis, right ventricular dysfunction, arrhythmias and other congenital cardiac anomalies, the patient was followed up with medical treatment.

\section{DISCUSSION}

EA was first reported by German physician Wilhelm Ebstein in 1866 (5). The basic anatomical abnormality consists of displacement of the septal and posterior leaflets of the tricuspid valve from the atrioventricular annulus into the body of the right ventricle, which results in atrialization of a portion of the right ventricle. The anterior leaflet is also abnormal and typically has a sail-like appearance. The spectrum of the malformation in EA may range from only minimal displacement of the septal and posterior leaflets to an imperforate membrane or muscular shelf between the inlet and trabecular zones of the right ventricle. In patients with EA, the downward displacement of the septal and posterior leaflets in relation to the anterior mitral valve leaflet is $>8 \mathrm{~mm} / \mathrm{m}^{2}$ considering the body surface area (6). In the current case, the apical displacement of the septal leaflet in relation to the anterior mitral valve leaflet was $12 \mathrm{~mm} / \mathrm{m}^{2}$.

Several definitions have been used to describe the anatomical severity of EA. Carpentier et al (7) proposed the following classification for EA: type A, the volume of the true right ventricle is adequate; type $\mathrm{B}$, a large atrialized component of the right ventricle exists, but the anterior leaflet of the tricuspid valve moves freely; type C, the anterior leaflet is severely restricted in its movement and may cause significant obstruction of the right ventricular outflow tract; and type $\mathrm{D}$, almost complete atrialization of the ventricle except for a small infundibular component. Our patient had a type A EA in which the right ventricle was smaller than usual, but hemodynamically well functioning, explaining why she remained asymptomatic and undiagnosed until her 90s.

Patients with EA may have symptoms associated with right heart failure because of the enlarged and dysfunctional right ventricle

${ }^{1}$ Department of Cardiology, Kosuyolu Kartal Heart Training and Research Hospital, Istanbul; ${ }^{2}$ Department of Cardiology, Kars Kafkas University, Faculty of Medicine, Kars, Turkey

Correspondence: Dr Mahmut Yesin, Denizer Cad. Cevizli Kvs. No:2 Cevizli Kartal/Istanbul, Turkey. Telephone 90-532-4726596, fax-90-216-4596321, e-mail mahmutyesin@yahoo.com 


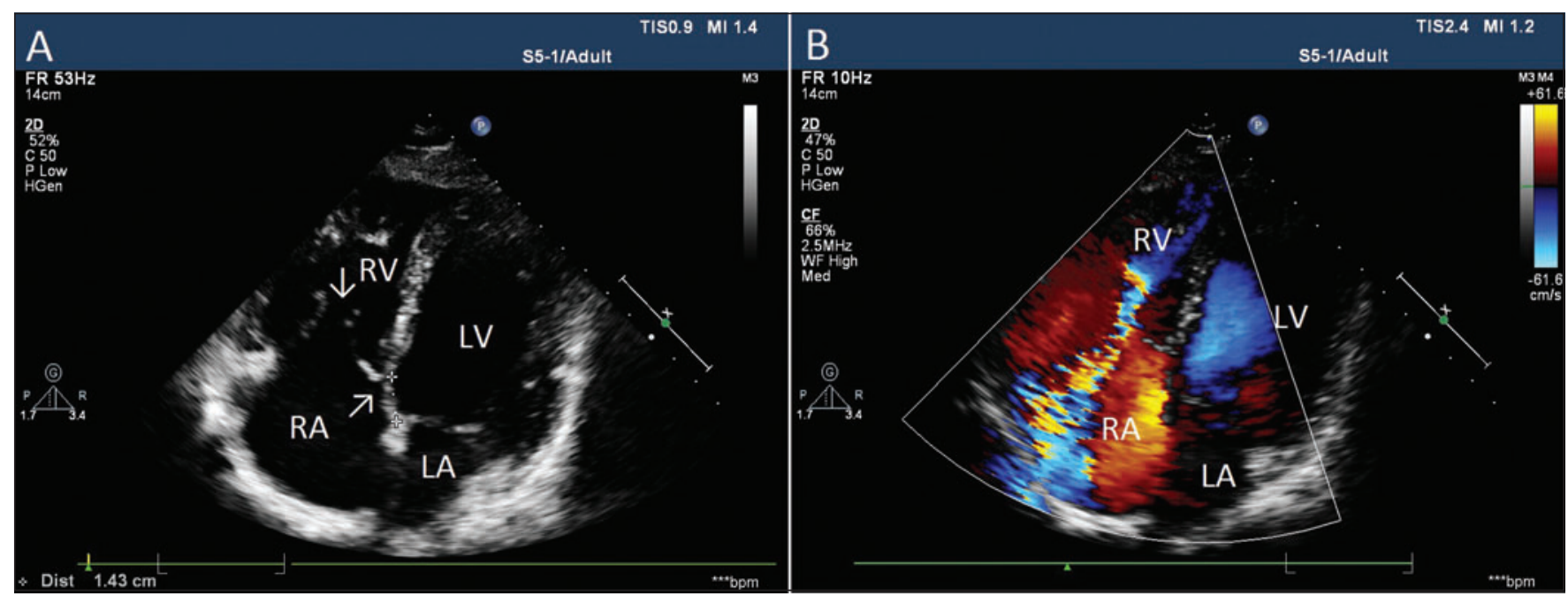

Figure 1) Transthoracic echocardiography apical four-chamber view shows apical displacement of the septal leaflet of the tricuspid valve (arrow) causing atrialization of a section of the right ventricle $(R V)$ leaving a relatively small but functional $R V(A)$. Colour Doppler imaging demonstrated severe tricuspid regurgitation due to central coaptation failure of tricuspid leaflets (B). LA Left atrium; LV Left ventricle; RA Right atrium

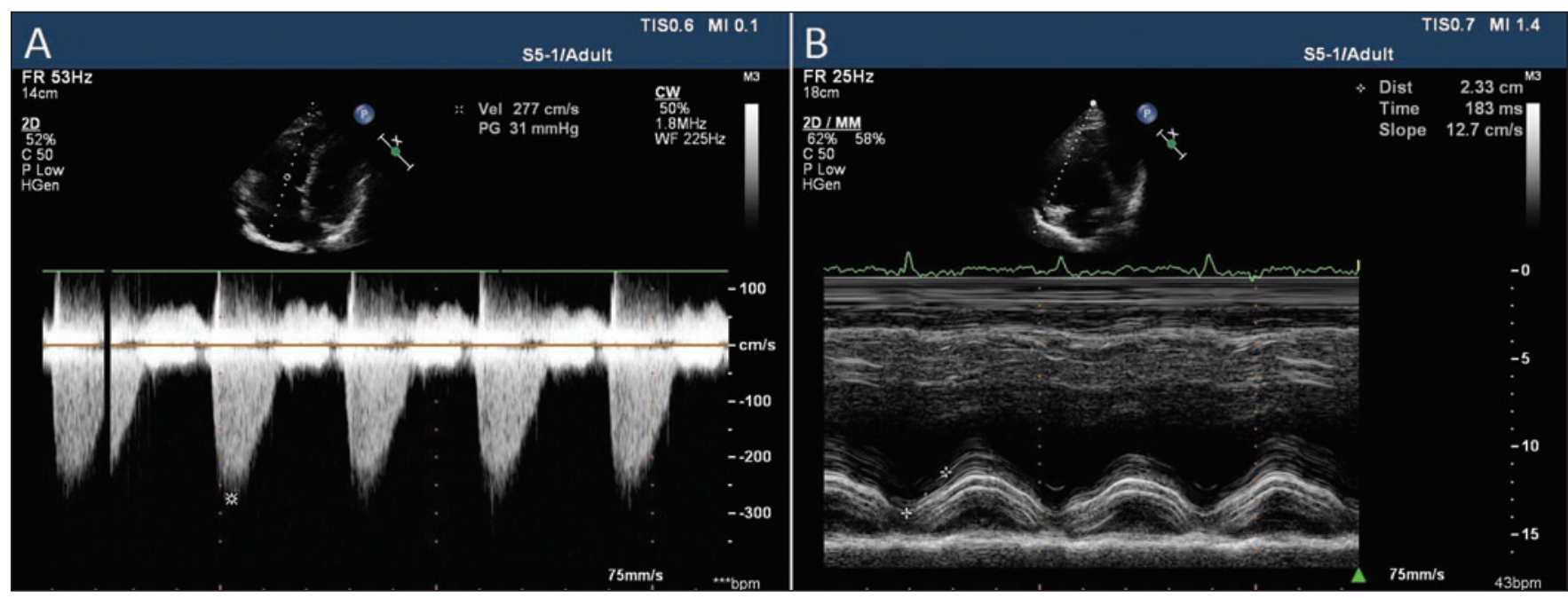

Figure 2) Systolic pulmonary artery pressure of $35 \mathrm{mmHg}$ was estimated from the tricuspid regurgitant jet with continuous wave Doppler imaging (A). Tricuspid annular plane systolic excursion was measured as $23 \mathrm{~mm}$ using M-mode echocardiography (B)

compressing the left ventricle. Substantial cyanosis, poor functional capacity, arrhythmias, paradoxical embolism and sudden cardiac death may occur. It may present at any age, with a variety of hemodynamical and electrophysiological manifestations. If the deformity of the tricuspid valve is severe, neonatal congestive heart failure or even intrauterine death may occur. On the other hand, patients with isolated minor tricuspid valve displacement may remain asymptomatic until late adult life, as in the present case (4).

Significant hemodynamic and physiological changes occur during pregnancy, some of which may adversely affect the hemodynamic status of a patient with EA. Despite increased cardiac output, stroke volume, heart rate and reduced peripheral vascular resistance, pregnancy appears to be well tolerated in the majority of women with EA (8). In the present case, the patient had given birth by vaginal delivery seven times without any complication.

Observation alone is advised for asymptomatic patients with no right-to-left shunting and only mild cardiomegaly. Children who have survived infancy generally do well for several years, and surgery can be postponed until symptoms appear, cyanosis becomes evident or paradoxical emboli occur. Once symptoms progress to New York Heart Association functional class III or IV, medical management has little to offer; surgery is clearly indicated despite the increased risks. In rare cases, patients with EA live $>70$ years, but one reported patient died at 85 years of age (9). Our 92-year-old patient is the oldest with EA reported in the current literature.

SUPPLEMENTARY DATA LEGENDS: Video 1. Transthoracic echocardiography apical four-chamber view shows a moderate dilation of right chambers with tethering of the septal and posterior leaflets of the tricuspid valve during systole and apical displacement of the septal leaflet of the tricuspid valve. Video 2. Transthoracic echocardiography colour Doppler imaging demonstrated severe tricuspid regurgitation due to central coaptation failure of tricuspid leaflets.

CONTRIBUTORSHIP: All of the authors contributed planning, conduct and reporting of the work. All contributors are responsible for the overall content as guarantors.

FUNDING: No funding was provided for this report.

DISCLOSURES: The authors have no conflicts of interest to declare. 


\section{REFERENCES}

1. Dearani JA, Danielson GK. Congenital heart surgery nomenclature and database project: Ebstein's anomaly and tricuspid valve disease. Ann Thorac Surg 2000;69:S106-S117.

2. Danielson GK, Driscoll DJ, Mair DD, et al. Operative treatment of Ebstein's anomaly. J Thorac Cardiovasc Surg 1992;104:1195-202.

3. Brown ML, Dearani JA, Danielson GK, et al. The outcomes of operations for 539 patients with Ebstein anomaly. J Thorac Cardiovasc Surg 2008;135:1120-36, e1-7.

4. Celermajer DS, Bull C, Till JA, et al. Ebstein's anomaly: Presentation and outcome from fetus to adult. J Am Coll Cardiol 1994;23:170-6.

5. Ebstein W. Ueber einen sehr seltenen Fall von Insufficienz der Valvula tricuspidalis, bedingt durch eine angeborene hochgradige Missbildung derselben. Arch Anat Physiol 1866;238-55.
6. Edwards WD. Embryology and pathologic features of Ebstein's anomaly. Prog Pediatr Cardiol 1993;2:5-15.

7. Carpentier A, Chauvaud S, Mace L, et al. A new reconstructive operation for Ebstein's anomaly of the tricuspid valve. J Thorac Cardiovasc Surg 1988;96:92-101.

8. Connolly HM, Warnes CA. Ebstein's anomaly: Outcomes of pregnancy. J Am Coll Cardiol 1994;23:1194-8.

9. Giuliani ER, Fuster V, Brandenburg RO, Mair DD. Ebstein's anomaly: The clinical features and natural history of Ebstein's anomaly of the tricuspid valve. Mayo Clin Proc 1979;54:163-73. 